WRPS-43539

Revision 0

\title{
Environmental Monitoring of Leaks using Time Lapsed Long Electrode Electrical Resistivity
}

Prepared for the U.S. Department of Energy

Assistant Secretary for Environmental Management

Contractor for the U.S. Department of Energy

Office of River Protection under Contract DE-AC27-08RV14800

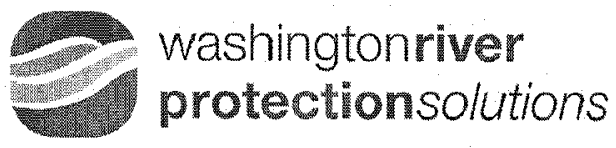

P.O. Box 850

Richland, Washington 99352 
WRPS-43539

Revision 0

\section{Environmental Monitoring of Leaks using Time Lapsed Long Electrode Electrical Resistivity}

D. F. Rucker

ARCADIS U.S., Inc.

M. H. Loke

Geotomo Software
J. B. Fink

hydroGEOPHYSICS, Inc.

D. A. Myers

Washington River Protection Solutions

Date Published

November 2009

To Be Presented at

American Geophysical Union

Washington, D.C.

Published in

Geophysical Research Letters

Prepared for the U.S. Department of Energy

Assistant Secretary for Environmental Management

Contractor for the U.S. Department of Energy

Office of River Protection under Contract DE-AC27-08RV14800

\section{washingtonriver}

protectionsolutions

P.O. Box 850

Richland, Washington

Copyright License

By acceptance of this article, the publisher and/or recipient acknowledges the U.S. Government's right to retain a nonexclusive, royalty-free license in and to any copyright covering this paper.

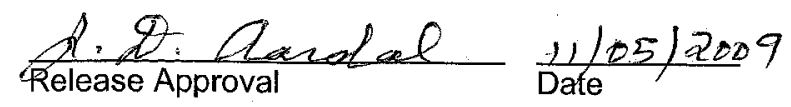

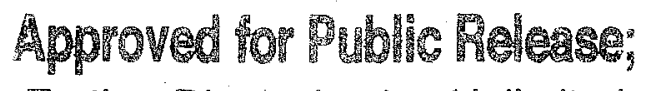
Furher Dissemination Unlimited 


\section{LEGAL DISCLAIMER}

This report was prepared as an account of work sponsored by an agency of the United States Government. Neither the United States Government nor any agency thereof, nor any of their employees, nor any of their contractors, subcontractors or their employees, makes any warranty, express or implied, or assumes any legal liability or responsibility for the accuracy, completeness, or any third party's use or the results of such use of any information, apparatus, product, or process disclosed, or represents that its use would not infringe privately owned rights. Reference herein to any specific commercial product, process, or service by trade name, trademark, manufacturer, or otherwise, does not necessarily constitute or imply its endorsement, recommendation, or favoring by the United States Government or any agency thereof or its contractors or subcontractors. The views and opinions of authors expressed herein do not necessarily state or reflect those of the United States Government or any agency thereof.

This report has been reproduced from the best available copy. Available in paper copy. 
WRPS-43539

Environmental Monitoring of Leaks using Time Lapsed Long Electrode Electrical Resistivity

Dale F. Rucker

ARCADIS U.S., Inc

3777 E Broadway Blvd, Suite 100

Tucson, AZ 85716

(520) 9076063

druck8240@gmail.com

James B. Fink

hydroGEOPHYSICS, Inc.

2302 N Forbes Blvd

Tucson, AZ 85715

(520) 6473315

ifink@hgiword.com

Meng H. Loke

Geotomo Software

115 Cangkat Minden Jalan 5

Minden Heights, 11700 Gelugor

Penang, Malaysia

drmhloke@yahoo.com

\section{Acknowledgements}

Special thanks to Dave Myers of Washington River Protection Solutions for reviewing the paper. Also thanks to Marc Levitt and Kraig Williams for data acquisition. This work was performed under U.S. Department of Energy contract DE-AC27-08RV14800.

Key Terms:

0520 Data analysis: algorithms and implementation

0594 Instruments and techniques

0925 Magnetic and electrical methods (5109)

1875 Vadose zone

1803 Anthropogenic effects $(4802,4902)$ 


\title{
Environmental Monitoring of Leaks using Time Lapsed Long Electrode Electrical Resistivity
}

\begin{abstract}
Highly industrialized areas pose significant challenges for surface based electrical resistivity characterization and monitoring due to the high degree of metallic infrastructure. The infrastructure is typically several orders of magnitude more conductive than the desired targets, preventing the geophysicist from obtaining a clear picture of the subsurface. These challenges may be minimized if steel-cased wells are used as long electrodes. We demonstrate a method of using long electrodes in a complex nuclear waste facility to monitor a simulated leak from an underground storage tank. The leak was simulated by injecting high conductivity fluid in a perforated well and the resistivity measurements were made before and after the leak test. The data were processed in four dimensions, where a regularization procedure was applied in both the time and space domains. The results showed a lowered resistivity feature develop south of the injection site. The time lapsed regularization parameter had a strong influence on the differences in inverted resistivity between the pre and post datasets, potentially making calibration of the results to specific hydrogeologic parameters difficult.
\end{abstract}

\section{Introduction}

The Hanford Site in southeastern Washington has 177 underground liquid waste storage tanks with nearly $210 \times 10^{6} \mathrm{~L}$ of highly radioactive legacy waste. The waste was generated from plutonium production for nuclear weapons. Of these, 67 single shelled tanks are known or suspected as having leaked, possibly releasing an estimated $4 \times 10^{6} \mathrm{~L}$ of radioactive fluids into the vadose zone [Gephart and Lundgren 1998]. The Department of Energy is currently conducting liquid waste retrieval to temporarily house the waste into safer double shelled tanks and eventually into a vitrified waste matrix for permanent disposal.

The waste tanks are grouped together in a number of tank farms, which are highly complex industrial areas with below ground piping networks, distribution manifolds and divergence boxes needed to move the waste from the generating plant to specific tanks, electricity distribution networks, and other waste retrieval infrastructure. Routine leak detection is conducted either through liquid level monitoring inside the tank or soil monitoring outside the tank. Unfortunately, intra-tank monitoring is not reliable during retrieval due to the nature of the retrieval operations and changing liquid levels.

Remote sensing ex-tank methods are also used within the tank farms for routine characterization and retrieval monitoring. Steel-cased leak detection wells are placed around each tank for use by down-hole geophysical logging tools [Gee et al., 2007]. Unless multiple tools are used, however, it would take several days to log all wells around a tank. Instantaneous leak detection is impossible with the borehole logging methods. Additionally, these borehole tools have limited volume sensing capabilities [Koizumi et al., 1994], making them susceptible to missing a leak. Surface based electrical resistivity characterization (ERC) has the potential to overcome these issues. 
Ramirez et al. [1996] and Daily et al. [2004] described several resistivity methodologies that could be used around a leaky tank, including the incorporation of steel-cased wells as long electrodes. Burke [2006] and Schofield [2006] also described a time series based transfer resistance monitoring with long electrodes around the storage tanks using the patented methodology by Fink [2006]. Rucker et al. [2009] demonstrated that the long electrode ERC method can be used to define the spatial distribution of historical leaks in an actual tank farm at Hanford.

The work presented here continues the work by Rucker et al. [2009] by demonstrating a field experiment using time lapsed electrical resistivity monitoring with wells positioned around several tanks (i.e., 4D long electrode resistivity monitoring). The resistivity data were collected as independent snapshots before and after a leak injection test within the $\mathrm{S}$ tank farm, and the snapshots were inverted together using a smooth regularization method in both time and space domains. Given the speed of data acquisition on a limited subset of wells and highly efficient computational platforms, the method could conceptually be applied in near real time to monitor for leaks during waste retrieval.

\section{Method}

\subsection{Leak Injection Test}

The S tank farm is located in the southern portion of the 200 West Area of Hanford's central plateau. The $\mathrm{S}$ tank farm is one of 12 on the Hanford Site and is bordered by the SY tank farm on the northeast corner and the SX tank farm to the south. The tank farm is organized such that the tanks are aligned in rows with three tanks per row. Numbering of the tanks start with S101 in the norheast corner of the farm and S112 is in the southwest corner. The tanks are approximately $23 \mathrm{~m}$ in diameter with a capacity of $2870 \mathrm{~m}^{3}$ (758,000 gallons). The tanks of interest for this study is S102, which is the middle tank in the northernmost row and S104 directly southeast of S102.

A series of tank leaks were simulated in the S tank farm around tank S102 to test the effectiveness of several resistivity based geophysical methods to quantify these leaks [Rucker and Fink, 2007]. The leak injection system included the use of a leak detection monitoring well (40 0210 at the 10 o'clock position around tank S102) for injection of the tank waste simulant. The well was converted from a leak detection well to an injection well by perforating the $15 \mathrm{~cm}$ diameter carbon steel pipe from 15 to $33 \mathrm{~m}$ below ground surface and plugging the well below the perforated zone. The perforated zone was designed to simulate a leak from the tank bottom. The simulated waste consisted of a $25 \%$ (by volume) sodium thiosulfate pentahydrate solution with a specific gravity of approximately 1.138 at a temperature of 23.1 degrees Celsius. The simulant had electrical properties similar to the radioactive waste stored in underground tanks. The simulated leaks occurred over a 3 month period with a total $50 \times 10^{3} \mathrm{~L}$ of solution injected into the subsurface.

\subsection{Resistivity Monitoring}

Prior to the leaks, an ERC survey was conducted in the S tank farm to establish a baseline condition for comparison with the post leak test condition. The survey included resistivity measurements on the steel-cased wells using a SuperSting R8 (i.e., eight simultaneous 
recording channels) resistivity data acquisition system (Advanced Geosciences, Inc. Austin, TX). Data acquisition took approximately $40 \mathrm{~min}$ to complete a full reciprocal data set on 32 wells with a measurement time of $3.6 \mathrm{~s}$ per cycle and two cycles per reading.

The survey design, acquisition, and processing methodology was similar to the long electrode characterization conducted by Rucker et al. [2009] in the T tank farm, where the wells were used as both current transmission and voltage receiving electrodes. The pole-pole configuration was used, and the remote electrodes were located approximately $1500 \mathrm{~m}$ away in nearly opposite directions. The steel-cased monitoring wells were dispersed near the footprint of the northern tanks S101 through S106. The monitoring wells were typically less than $42 \mathrm{~m}$ in length, with the water table at approximately $70 \mathrm{~m}$ below ground surface.

Approximately one month after the cessation of the injection testing, a follow-on resistivity survey was completed on the same wells as the pre injection survey. Figure 1 shows the scatter of the data for the pre and post injection, with data presented as apparent resistivity. The apparent resistivity was calculated the same as if it were a point electrode. The pre leak data in Figure 1a shows low scatter among reciprocal measurements, whereas the post leak reciprocal measurements exhibited higher scatter. The reciprocal error was used as a means for data rejection, with those data outside the $5 \%$ range eliminated from the dataset. Of the 992 combinations, 46 were rejected for high reciprocal errors. Figure 1c shows the scatter of pre to post leak apparent resistivity data. The data within Figure 1c were used for inverse modeling. 

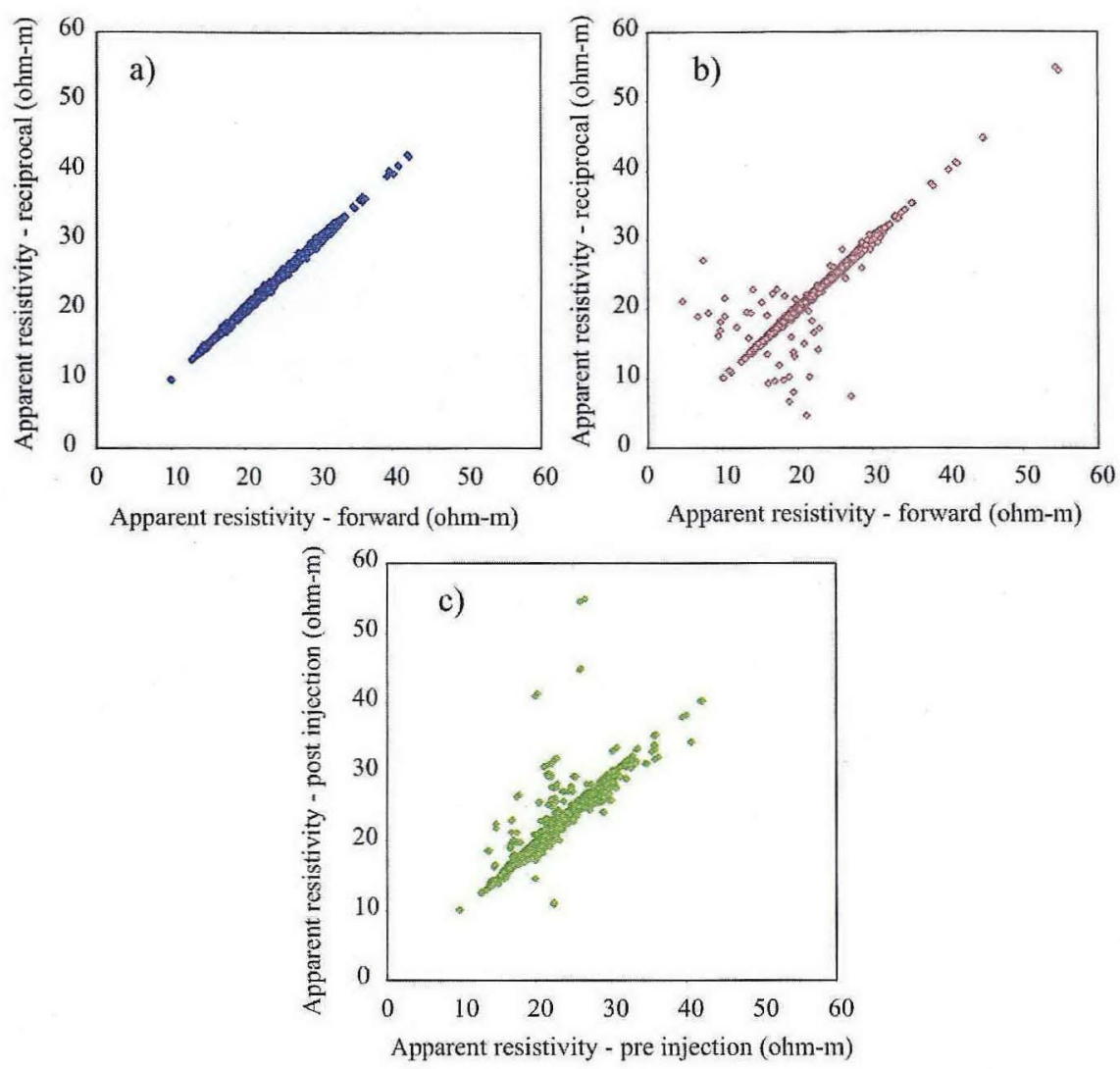

Figure 1. Apparent resistivity data acquired in the S tank farm of Hanford using long electrodes a) reciprocal data scatter for pre injection survey, b) reciprocal data scatter for post injection survey, c) pre and post injection data scatter.

\section{Numerical Modeling}

The three dimensional inversion of long electrode data is similar to that presented in Loke and Dahlin [2002] and Loke et al. [2003], with either the L2 norm smoothness constrained least squares that aims to minimize the square of the misfit between the measured and modeled data [deGroot Hedlin and Constable, 1990; Ellis and Oldenburg, 1994]:

$$
\left(\mathbf{J}_{i}^{T} \mathbf{J}_{i}+\lambda_{i} \mathbf{W}^{T} \mathbf{W}\right) \Delta \mathbf{r}_{i}=\mathbf{J}_{i}^{T} \mathbf{g}_{i}-\lambda_{i} \mathbf{W}^{T} \mathbf{W} \mathbf{r}_{\mathbf{i}-1}
$$

or the L1 norm that minimizes the sum of the absolute value of the misfit:

$$
\left(\mathbf{J}_{\mathbf{i}}^{\mathrm{T}} \mathbf{R}_{\mathrm{d}} \mathbf{J}_{\mathbf{i}}+\lambda_{i} \mathbf{W}^{\mathrm{T}} \mathbf{R}_{\mathbf{m}} \mathbf{W}\right) \Delta \mathbf{r}_{i}=\mathbf{J}_{\mathbf{i}}^{\mathrm{T}} \mathbf{R}_{\mathrm{d}} \mathbf{g}_{\mathbf{i}}-\lambda_{i} \mathbf{W}^{\mathrm{T}} \mathbf{R}_{\mathbf{m}} \mathbf{W} \mathbf{r}_{\mathbf{i}-1}
$$

where $g$ is the data misfit vector containing the difference between the measured and modeled data, $\mathbf{J}$ is the Jacobian matrix of partial derivatives, $\mathbf{W}$ is the spatial roughness filter, $\mathbf{R}_{\mathbf{d}}$ and $\mathbf{R}_{\mathbf{m}}$ are the weighting matrices to equate model misfit and model roughness, $\Delta \mathbf{r}_{\mathbf{i}}$ is the change in model parameters for the $\mathrm{i}^{\text {th }}$ iteration, $\mathbf{r}_{\mathbf{i}}$ is the model parameters for 
the previous iteration, $\mathrm{i}$, and $\lambda_{\mathrm{i}}$ is the Lagrangian spatial dampening factor. The logarithms of the model resistivity and measured apparent resistivity values are used as the model parameters and data respectively in the above equations. Additionally, for long electrodes, the model cells at the well's location are given a fixed low resistivity value, say $0.001 \mathrm{ohm}-\mathrm{m}$, for the duration of the model's iterative inverse procedure.

To simulate a 4D inversion that accommodates both time and space domains, we take the approach demonstrated by Kim et al. [2009]. The time domain is incorporated directly into the regularization procedure by modifying Equation 1 above:

$$
\left(\mathbf{J}_{\mathbf{i}}^{\mathrm{T}} \mathbf{J}_{\mathbf{i}}+\lambda_{i} \mathbf{W}^{\mathrm{T}} \mathbf{W}+\alpha \mathbf{M}^{\mathrm{T}} \mathbf{M}\right) \Delta \mathbf{r}_{\mathbf{i}}=\mathbf{J}_{\mathbf{i}}^{\mathrm{T}} \mathbf{g}_{\mathbf{i}}-\lambda_{i} \mathbf{W}^{\mathrm{T}} \mathbf{W} \mathbf{r}_{\mathbf{i}-1}-\alpha \mathbf{M}^{\mathrm{T}} \mathbf{M} \mathbf{r}_{\mathbf{i}-\mathbf{1}}
$$

where $\mathbf{M}$ is the difference matrix applied across the time models with only the diagonal and one sub diagonal elements having values of 1 and -1 , respectively. Similar in concept to the spatial roughness filter, the temporal roughness filter, $\mathbf{M}$, minimizes the difference in the resistivity of each model cell and the corresponding cell for the next temporal model. The time lapsed parameter $\alpha$ is the temporal dampening factor that gives the relative importance weight for minimizing the change in the resistivity between one temporal model and the next model. Equation 3 assumes the electrical resistivity varies smoothly in time and space, and the degree of smoothness is controlled through $\alpha$ by the user. Higher values of $\alpha$ will result in time lapsed inverted models that are more similar to one another. A value of zero for the time lapsed parameter equates to no time regularization.

\section{Results}

The 4D time lapsed long electrode resistivity modeling was conducted with the software RES3DINVx64, a 64 bit parallel processing resistivity inversion code (Geotomo Software, Malaysia). The computer platform was the Dell PowerEdge R900 with 4 quadcore Xeon $2.93 \mathrm{GHz}$ processors and 128GB of RAM. The inversion modeling for the two snapshots typically finished in less than 70 minutes with six iterations and a final RMS less than $15 \%$.

Figure 2 shows the results of the inversion as color contour plots of the uppermost layer in the model. Rucker et al. [2009] demonstrated that the long electrode inversion results typically have a funnel shape, where the low resistivity target has the largest footprint at the surface. The intensity of the target decreases with depth likely due to a modeling artifact when incorporating wells with finite resistivity, in this case $0.001 \mathrm{ohm}-\mathrm{m}$. The model assumes that a point source electrode is used at the surface and the current density along the length of the well decreases with depth. In this way, the vertical information is lost because all target information is assumed to exist at the highest current density. 

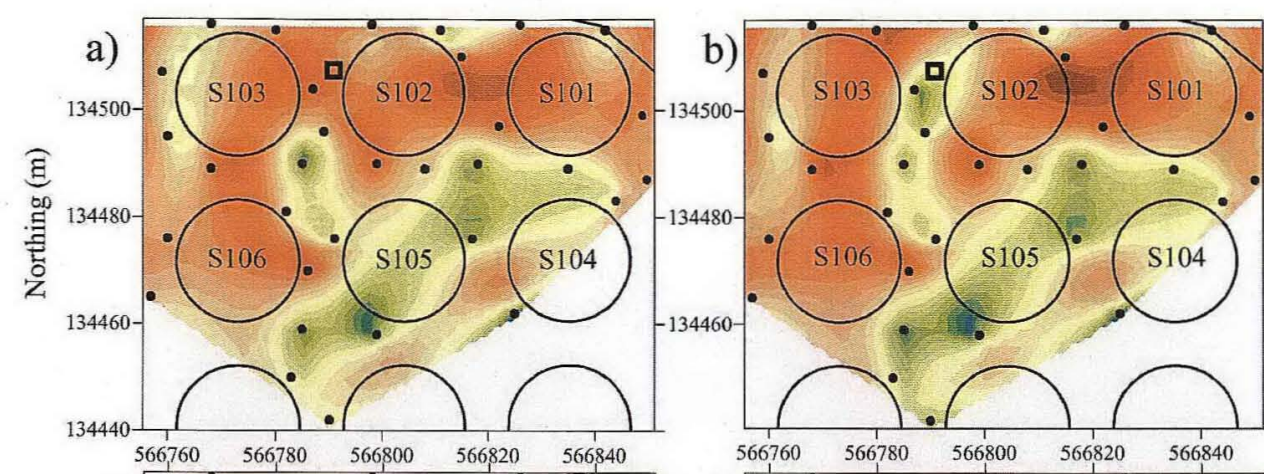

$\log$ Resistivity

(ohm-m)

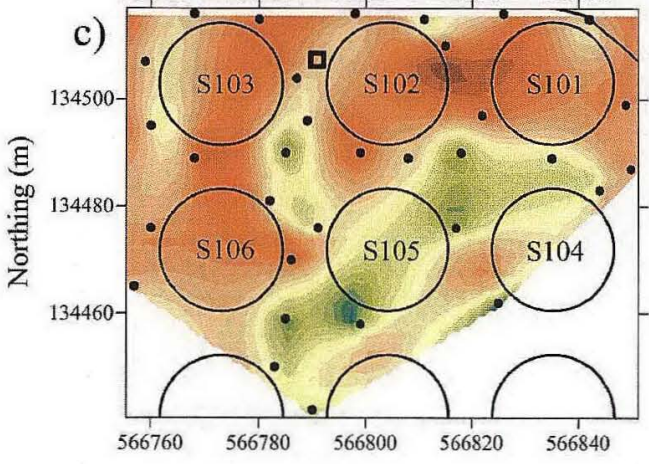

d)

d)
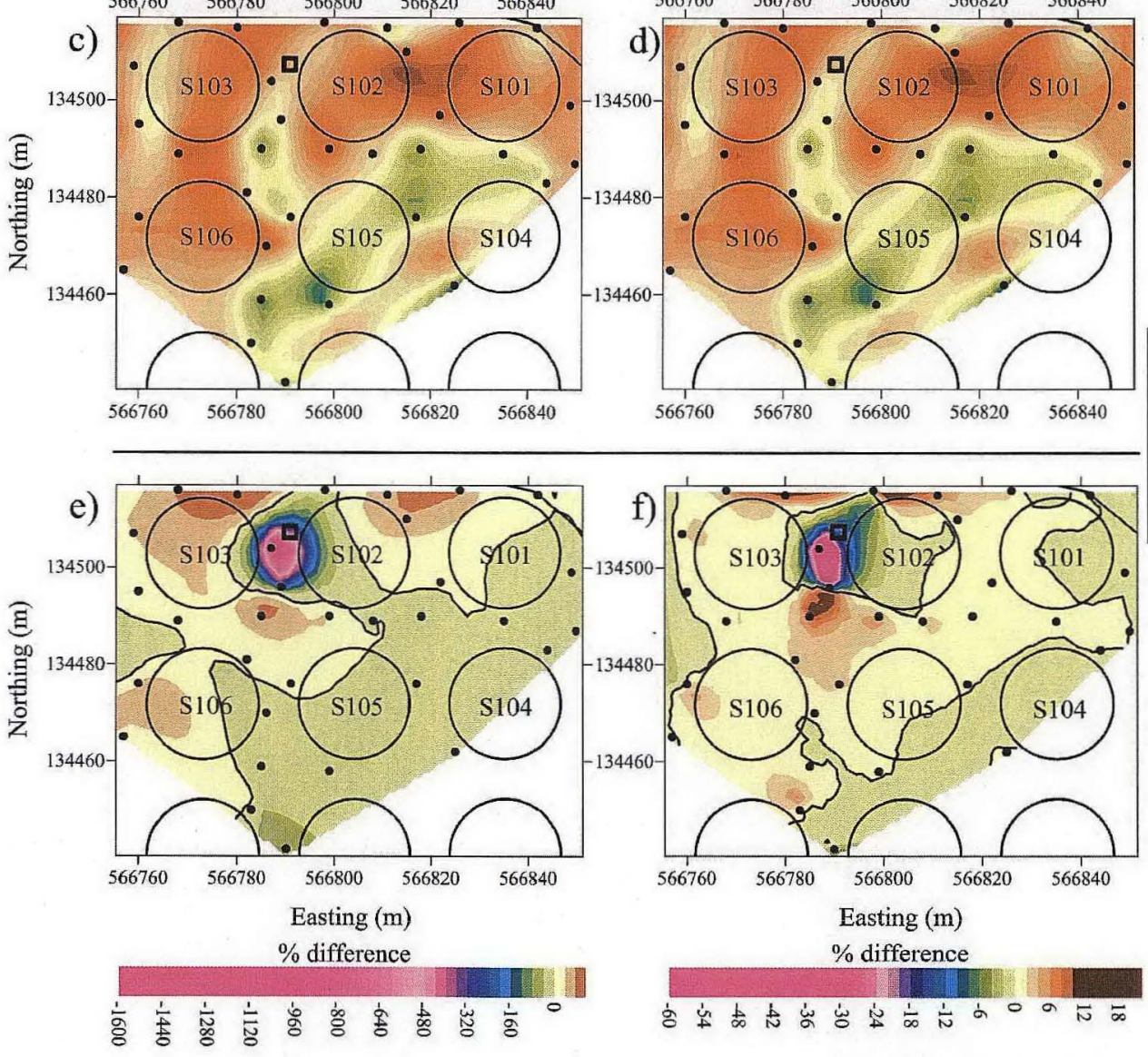

\begin{tabular}{|ll}
\hline & Legend \\
- & long electrode \\
\hline & injection well
\end{tabular} $\bigcirc_{\text {tank footprint }}^{\text {injection well }}$

Figure 2. Results of time lapsed modeling of long electrode data. a) pre leak resistivity with $\alpha=0.001, \mathrm{~b}$ ) post leak resistivity with $\alpha=0.001, \mathrm{c}$ ) pre leak resistivity with $\alpha=0.1, \mathrm{~d}$ ) post leak resistivity with $\alpha=0.1$, e) percent difference between pre and post for $\alpha=0.001$, f) percent difference for $\alpha=0.1$. The solid line in e) and f) represent a percent resistivity change of zero.

The top four models, Figures 2a-d, show the logarithm of electrical resistivity for two snapshots for two time lapsed parameter values. Figures $2 \mathrm{a}$ and $2 \mathrm{~b}$ represent the before and after leak injection test results with $\alpha=0.001$, and Figures $2 \mathrm{c}$ and $2 \mathrm{~d}$ represent before and after with $\alpha=0.1$. In each figure, the lower left and right hand corners have been blanked to remove resistivity data. The blanking was based on the absence of wells in 
the area and the extremely low sensitivity of those cells to the final resistivity distribution.

The pre leak results in Figures 2a and 2c show a low resistivity target north of tank S104 and extending west southwest across S105. From historical characterization records and inventory reports, it is likely that tank S104 lost approximately $9.1 \times 10^{4} \mathrm{~L}$ of highly saline waste to the subsurface and the pre leak assessment is mapping the footprint of the leak. The post leak results in Figures $2 b$ and $2 d$ show a slight decrease in resistivity near the injection well (square symbol) at the northwest corner of S102.

The change in resistivity with $\alpha=0.001$ was more significant than $\alpha=0.1$ and Figures $2 \mathrm{e}$ and $2 \mathrm{f}$ show these differences quantitatively. The percent difference was calculated on a cell-by-cell basis as the [(after-before)/before*100] and negative percent differences reflect areas becoming more conductive. Both sets of models showed a logical placement of the lowered resistivity near the injection well and both showed a similar shape to the distribution of positive and negative changes (a percent change of zero is distinguished by a solid contour line). The similarity ends, however, with the intensity of those changes as indicated by the associated color scales. The smaller $\alpha$ parameter represented in Figure 2e showed that the scale of change was much greater than the larger $\alpha$ parameter.

Figure 3 shows the pre and post leak resistivity for a model cell $8 \mathrm{~m}$ to the south of the injection well for a full range of $\alpha$ values. As $\alpha$ increases, the resistivity curves monotonically converge towards a single value (approx. $119 \mathrm{ohm}-\mathrm{m}$ ) and the percent difference between the pre and post model results nears zero. The time regularization appears to affect the pre leak resistivity modeling much greater than the post leak modeling at this cell. An inspection of behavior of different cells around the entire domain shows that the behavior can be wildly different with the movement of pre and post resistivity changing directions through $\alpha$ space. The common thread throughout the domain, however, is that the percent change in all cells tends toward zero as $\alpha$ increases.

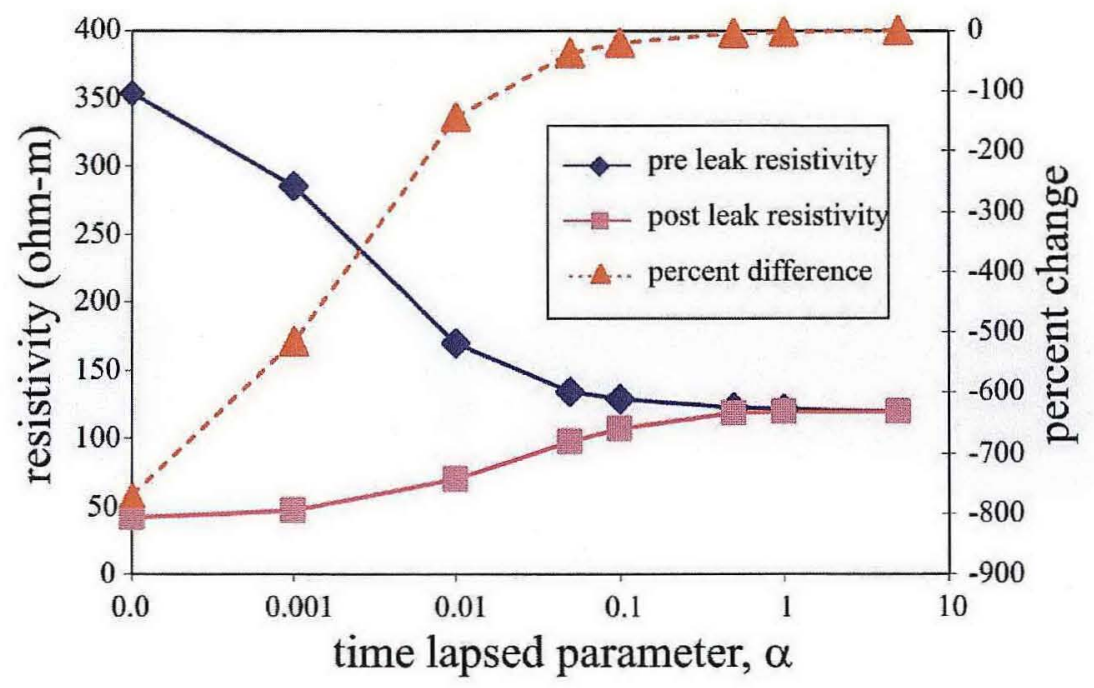


Figure 3. Resistivity of a model cell $8 \mathrm{~m}$ south of the injection site versus time lapsed parameter, $\alpha$.

\section{Conclusions}

A time lapsed study of electrical resistivity using long electrodes was conducted at an industrial site to track the movement of an injected saline tracer into the vadose zone. The Hanford site has been the focus of several surface based resistivity projects in the past to map contaminant plumes resulting from direct disposal of liquid waste to the ground [Rucker and Fink, 2007; Rucker et al., 2010]. The Hanford site is generally well suited for the technique given the contrast between the resistive host sands and conductive waste. The long electrode technique was chosen for the present study due to the highly complex nature of the focus area (the S tank farm), with its vast amounts of metallic infrastructure that could potentially interfere with surface electrode measurements. Rucker et al. [2009] demonstrated through example models and field study of a similar tank farm that the long electrode resistivity method using steel-cased wells as electrodes could map the footprint of plumes beneath tanks that were assumed to have leaked sometime in the past.

The time lapsed study incorporated a time regularization scheme in the inverse model to smooth the variability across multiple snapshots. The time lapsed parameter, $\alpha$, controls the degree of smoothing with larger values decreasing the expected variability. The inverse modeling was conducted by examining the effect of $\alpha$ on the model outcome. The differences between pre and post injection were presented simply as the percent difference between before and after. The results showed that the time lapsed parameter can have a dramatic effect on the intensity of the changes. Small values of $\alpha$ provided minimal restriction and the pre and post values at select cells were seen to differ by a factor of 10 or more near the injection site. Larger values of $\alpha$ were seen to restrain those differences. Consistently throughout the domain, as the time lapsed parameter increased, the percent difference between pre and post injection converged towards zero.

Although the intensity varied greatly, the shape of the target was relatively consistent for all models. The injection of a highly saline solution into the vadose zone caused a lowered resistivity feature to appear moving to the south from the injection site. This consistency in shape and location for multiple models reinforces the hypothesis that long electrodes can be used to monitor dynamic events of the subsurface. Unfortunately, understanding those results in a hydrogeologic framework will be difficult. Since the long electrode technique destroys vertical information and the regularization in both space and time smoothes the degree of resistivity from one point to the next, calibration of the resistivity data will be tenuous if laboratory petrophysical models have been developed to convert the temporal changes in resistivity to changes in moisture content or contaminant concentration. Singha and Gorelick [2006] summarized the complications of calibrating results in this manner, including the mismatch in scale between measurement modalities and decreased sensitivity of the resistivity method away from the electrodes. They conclude that the field-scale relations between electrical resistivity and the hydrogeological parameter must be site, survey, and inversion specific. 
As for a near real-time monitoring tool, the time lapsed long electrode resistivity method has the potential to turn around information quickly. An eight-channel acquisition system can conceivably acquire data in approximately 12 min without reciprocals. A system where the channel count is equal to the number of electrodes would minimize the total time needed to acquire data. The processing time, however, is currently the limiting factor and a one-hour old model is the quickest turnaround observed. As computing platforms become larger, the time needed to conduct this step will also reduce. In the mean time, simple time series measurements of transfer resistance on multiple long electrode pairs is the fastest leak detection method deployed at Hanford [Burke, 2006].

\section{References}

Burke, C.A, Tank 241 S 102 High Resolution Resistivity Leak Detection and Monitoring Testing Report, RPP 30121, CH2M HILL Hanford Group, Inc., Richland, Washington, 2006.

Daily, W., A. Ramirez, and A. Binley, Remote Monitoring of Leaks in Storage Tanks using Electrical Resistance Tomography: Application at the Hanford Site, J. Environmental and Engineering Geophysics, 9, 11-24, 2004.

deGroot Hedlin, C., and S.C. Constable, Occam's inversion to generate smooth, two dimensional models from magnetotelluric data, Geophysics, 55, 1613-1624, 1990.

Ellis, R.G., and D.W. Oldenburg, Applied geophysical inversion: Geophysical Journal International, 116, 5-11, 1994.

Fink, J. B., Estimation of leakage rates using voltage measurements. US Patent 7,141,982 B2; November 28, 2006.

Gee, G.W., M. Oostrom, F.D. Freshley, M.L., Rockhold, and J.M. Zachara, Hanford site vadose zone studies: An overview, Vadose Zone Journal, 6, 899-905, 2007.

Gephart, R.E, and R.E Lundgren, Hanford Tank Cleanup: A Guide to Understanding the Technical Issues. Battelle Press, Columbus, OH, 1998.

Kim, J H., M J. Yi, S G., Park, and J.G. Kim, 4 D inversion of DC resistivity monitoring data acquired over a dynamically changing earth model, Journal of Applied Geophysics $68,522-532,2009$.

Koizumi, C .J., J. R. Brodeur, R. K. Price, J. E. Meisner, and D. C. Stromswold, High Resolution Gamma ray Spectrometry Logging for Contamination Assessment, Nuclear Geophysics 8, 149-164, 1994.

Loke, M.H. and T. Dahlin, A comparison of Gauss Newton and quasi Newton methods in resistivity imaging inversion, Journal of Applied Geophysics, 49, 149-162 ,2002. 
Loke, M.H., I. Acworth, and T. Dahlin, A comparison of smooth and blocky inversion methods in 2D electrical imaging surveys, Exploration Geophysics, 34, 182-187, 2003.

Ramirez A., W. Daily, A. Binley, and D. LaBrecque, Tank Leak Detection Using Electrical Resistance Methods. UCRL JC 122875, Preprint prepared for the Symposium on the Application of Geophysics to Engineering and Environment, Keystone, Colorado, Lawrence Livermore National Laboratory, Livermore, California, 1996.

Rucker, D.F., B.D. Cubbage, M.T. Levitt, and D.R. Glaser II, Electrical Resistivity Imaging to Monitor a Simulated Leak From an Underground Storage Tank at a Radiological Waste Facility. SAGEEP 2007, Annual meeting of the Environmental and Engineering Geophysical Society, Denver, CO. April 4-8, 2007.

Rucker, D.F. and J.B. Fink, Inorganic plume delineation using surface high resolution electrical resistivity at the $\mathrm{BC}$ cribs and trenches site, Hanford. Vadose Zone Journal 6, 946-958, 2007.

Rucker, D.F., M. H. Loke, M.T. Levitt, and G.E. Noonan, Electrical resistivity characterization of an industrial site using long electrodes. Geophysics (in review), 2009.

Rucker, D.F., M.T. Levitt, and W.J. Greenwood, Three dimensional electrical resistivity model of a nuclear waste disposal site. Journal of Applied Geophysics (in press), 2010.

Schofield, J.S, SST Deployment Demonstration and Injection Leak Testing of the HRR Long Electrode LDM System, RPP 17191, CH2M Hill Hanford Group, Inc., Richland, Washington, 2006.

Singha, K., and S.M. Gorelick, Effects of spatially variable resolution on field-scale estimates of tracer concentration from electrical inversions using Archie's law, Geophysics, 71, G83-G91, 2006

\section{Figure Captions}

